\title{
Automated Payment, Financial Decision-Making and a Public Policy Conundrum
}

\section{Introduction}

Credit card issuers across countries now offer automated payment facilities online to ensure that consumers commit to regular repayments. However, insofar it is unclear whether repayment automation leads to better financial decisions. With an average of $\$ 880$ billion of revolving debt in the U.S., it is no surprise that policy developers seek to remedy the global credit card debt problem. The current research makes three contributions. First, our study raises public awareness about the negative effects of automated payments on credit card repayments. Contrary to the established assumptions that autopay helps consumers to manage consumer finances (e.g., www.directdebit.co.uk), our experiment unanimously show that autopay facilities reduce the amount of credit card repayment. Second, our study offers a contemporary and relevant insight into the consumers' online credit card management, which is distinct from its offline counterpart. Specifically, in an online environment, consumers can process information on their credit card and saving almost simultaneously. For example, some consumers may access credit and saving accounts in different browser tabs, while others who own credit and saving accounts from the same institutions may be able to access both accounts within the same webpage. Finally, our study enriches understanding of individual differences in repayment decisions behaviour. Our results indicate that certain attitudinal tendencies to credit cards heightens the effect of autopay on repayment, but this effect is intensified when the context involves those with low level of saving.

\section{Conceptual Development}

\subsection{The Psychology of Automated Payment}

Credit cardholders often set up automatic monthly payments to avoid missed payments and incur penalties. The freedom and convenience associated with online banking means that credit card consumers can easily set up automated payment at an amount that they feel comfortable. Consumers can choose any amount ranging from the minimum amount, which is typically is set at $2 \%$ of the overall balance, to the full credit card balance. Prior research on goal pursuits suggests that people divide goals into subtasks to experience the motivational benefits of greater self-efficacy (Bandura, 1997). In this case, the use of automated repayment provides a sense of goal progress as it allows repayments to be made in smaller instalments, which in turn, bolsters one's perception of self-efficacy with respect to the overall goal (i.e. total credit card balance). However, a boosted sense of achievement resulting from subgoal completion may lead consumers to undermine absolute progress towards the overall goal. As such, the subgoal - rather than the superordinate goal - becomes the most salient point of reference for individuals' motivations towards goal pursuit (Besharat, Carrillat, \& Ladik, 2014). Unfortunately, the focus on subgoals can lead to a sense of complacency and reduced persistence towards superordinate goal (Gal \& McShane, 2012). Therefore, we expect that the presence of automated repayment cause consumers to focus on the more manageable subgoals (i.e., monthly repayments) rather than the unwieldy superordinate goals (i.e., total credit card balance).

In addition, we theorise that the convenience of automated payment removes the salience of the "pain of paying" (Prelec \& Loewenstein, 1998) away from future credit card repayment. A key characteristic of credit card expenses is that the "pain" of payment, which provides a nudge for self-reflection and intervention from overspending, is held at bay until the end of the month. However, with automated payment, such deliberation point is subverted 
to a one-time deliberation. Because automated payment shifts attention away from subordinate goals and reduces the complexity of monthly deliberation, we expect that consumers making automated credit card repayments will commit to less amount of repayment than those making non-automated payments.

H1: Automated payment leads to lower repayment amount compared to regular nonautomated payment.

\subsection{The Psychology of Credit and Saving Accounts}

The default setup of many credit card accounts tends to demarcate credit and debit (saving) accounts. For example, consumers may have separate login accounts to access information about their credit and debit accounts. Such financial accounts separation means that consumers also categorise debt and saving into separate mental accounts (Hershfield, Sussman, O’Brien, \& Bryan, 2015). Previous research suggests that such erroneous categorization of overall wealth can lead consumers to make financially detrimental decisions, such as taking on high-interest rate debt, while simultaneously holding money in low-interest rate saving account (Sussman \& O'Brien, 2015). The absence of overall wealth information in credit card accounts and statements means that people are likely to focus their attention to arbitrary information that may misshape one's perception of wealth.

We therefore expect that the absence of accurate information of financial capability in the form of saving account balance will lead consumers to anchor their repayment decisions on perceived wealth informed by the available credit limit. In contrast, the presence of saving information in credit card account has a direct influence over credit card repayment decision because it represents an accurate picture of one's overall wealth. Thus, higher (lower) balance of saving account will lead to higher (lower) credit card repayment. We expect that the positive effect of credit and saving account on repayment transcend over the effect of repayment mode (i.e. automated versus non-automated repayment) as it reconciles the consumers' saving and debt mental accounts. Hence:

H2: The amount in saving account influences the amount of credit card repayment.

\subsection{Individual Differences in Susceptibility to Credit Card Debts}

Prior studies regularly report that credit card as a payment mechanism yield psychological effect on the consumers' evaluation at the point of purchase. In comparison to more transparent and vivid payment methods such as cash, credit card payments causes consumers to trivialise past payment (Soman, 2001), reduces self-control (Chatterjee \& Rose, 2012) and overvalue past income (Soman \& Cheema, 2002). However, other studies suggest that consumers exhibit different individual differences in susceptibility to credit card's psychological effects (Awanis \& Cui, 2014; Rick, Cryder, \& Loewenstein, 2008). For example, those characterised as spendthrifts, instant gratifiers, low in self-regulation and financial sophistication are likely to emphasise on the bright side of credit cards (i.e., spending/lifestyle facilitator). Consequently, these consumers tend to overspend with their credit cards. We expect that such individual differences in credit card mentality will reflect on the consumers' repayment habits. Thus, we expect a negative relationship between individual-level susceptibility to credit card debts and repayment amounts.

In addition, we also expect that individual differences in credit card debts susceptibility will moderate the relationship between automated payment and repayment decision (H1). Indeed, those who advocate the bright side of credit card (high susceptibility) may appreciate, or even celebrate automated payment facilities, as it makes credit card experience more convenient and worry-free. To this end, we suggest that individual-level differences in susceptibility to credit card debts will moderate the relationship between automated payment and repayment amounts. 
Furthermore, we propose that such moderated relationship is stronger and consequently more problematic among those with constrained resources (low saving). Specifically, cash-strapped consumers are at risk of placing greater emphasis on the bright side of credit cards to make up for their lack of financial resources. The combined effects of individual susceptibility to credit card effects and the misguided promise of automated payment are likely to lead these individuals to a path of revolving debt. Meanwhile, those with sufficient resources are unlikely to suffer the same extent of indebtedness due to their wealth. Thus, we hypothesise that the moderating effect of individual susceptibility to credit card debts on the relationship between automated payment and repayment amount will differ across those with low and high saving:

H3: In low saving conditions, susceptibility to credit card debts moderates the relationship between automated payment and the amount of credit card repayment; in high saving no such moderation effect is expected.

\section{Method}

We conducted a 5 (current account balance) x 2 (payment mode) between-subject experiment involving a hypothetical scenario and repayment decisions. Current account balance has five levels: no account balance information (served as a control condition), $\$ 500$, $\$ 1000, \$ 2000$ and \$3000 and payment has two levels: autopay and regular payment. Across all experimental conditions, the minimum required payment and credit card balance were kept constant. In total, eight hundreds and nine US credit card users (458 women, 11\% were aged $18-44$ years, $42 \%$ from $25-34$ years, $24 \%$ from $35-44$ years and $23 \%$ were aged more than 45 years) were drawn from Amazon Mechanical Turk and were paid \$.35 each for participation. Participants were asked to imagine that they had just logged onto their online account where they could see their online credit card statement with a balance of $\$ 1.937 .28$ and a minimum payment of $£ 35.78$. This minimum required payment was equal to twopercent of balance. The amount of credit card balance reflects the U.S. average of consumer credit card balance (Salisbury, 2014). Participants were told that they also saw their current accounts (i.e., the amount of money in their debit cards) and were also told that they do not have any other forms of financial obligations. Participants were instructed to indicate the amount of credit card repayment they would make in the light of the information provided in the online statement.

We expect that the consumers' understanding of compounding interest will affect their credit card repayment decisions. Therefore, we controlled for the participants' financial knowledge, measured using three quiz-style questions following Navarro-Martinez, et al. (2011). Scores were calculated by tabulating the number of correct answers (one score for a right answer and zero for a wrong answer) and points are summed across the three questions to arrive at a single knowledge score. We measure participants' susceptibility to credit cards effect (SCCE) by a 12-items scale adapted from Awanis and Cui (2014) (Cronbach's $\alpha=0.89$ ). The scale has been found to be invariant across cultures e.g., UK and Singapore. The scale items used a 7 -point Likert format ( $1=$ strongly disagree, $7=$ strongly agree).

\section{Results and discussions}

A 5 (account balance) x 2 (payment mode) ANOVA revealed a main effect of current account balance, $\mathrm{F}(4,755)=61.50, \mathrm{p}<0.001, \eta^{2}=.246$, such that higher current account will lead to higher repayment $\left(\mathrm{M}_{\text {control }}=\$ 960.64(\mathrm{SD}=53.91), \mathrm{M}_{1}=\$ 181.85(\mathrm{SD}=58.08)\right.$, $\mathrm{M}_{2}=\$ 390.55(\mathrm{SD}=53.78), \mathrm{M}_{3}=\$ 1075.07(\mathrm{SD}=54.71), \mathrm{M}_{4}=\$ 1138.45(\mathrm{SD}=51.84)$, see Figure 1). The ANOVA design also revealed a main effect of autopay vs regular payment mode, 
$\mathrm{F}(1,755)=28.44, \mathrm{p}<0.001, \eta^{2}=.04$, such that the autopay $\left(\mathrm{M}_{\text {autopay }}=619.39, \mathrm{SD}=35.17\right)$ brought about lower payments than the regular mode $\left(\mathrm{M}_{\text {Regular }}=879.24, \mathrm{SD}=33.72\right)$. Therefore, $\mathrm{H} 1$ and $\mathrm{H} 2$ are supported.

Figure. 1. Mean payment amount as a function of level of current account and payment mode.

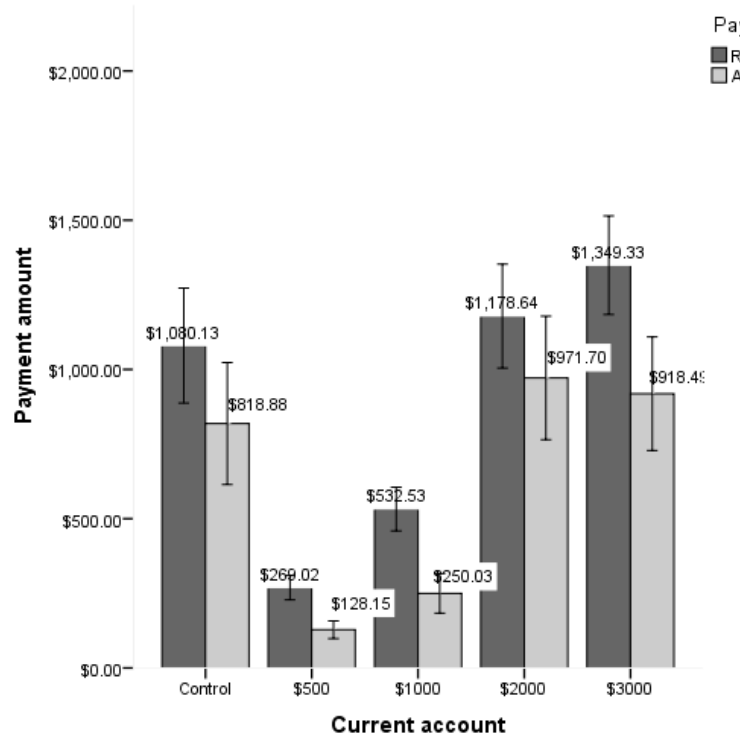

\subsection{Interaction effect of payment mode and susceptibility within low versus high account balance.}

We then examined the interaction effect of payment mode and susceptibility to credit card debt within three conditions: account balance is lower than the credit balance (high saving) and account balance is higher than the credit balance, and a control condition. We, therefore, recode the five levels of account balance experimental conditions into a dummy variable with three levels: 0 for control, 1 for low account balance and 2 for high account balance. The experimental conditions with account balance lower than the credit balance (i.e., $\$ 500$ and $\$ 1000$ ) is coded as 1 and those with account balance higher than the credit balance is coded as 2, no account balance information presented (i.e., control condition) is coded as 0 . We centred the means of SCCE and use a PROCESS macro (Hayes, 2013) to estimate the interaction effect.

Within low balance: the moderated regression results revealed the main effect of autopay $(b=-233.23, t=-7.46, p=<0.001)$, main effect of SCCE $(b=-43.318, t=13.04$, $\mathrm{p}=<0.001)$ and interaction effect between autopay and SCCE $(b=-81.48, \mathrm{t}=25.64, \mathrm{p}=<0.001)$ on credit card repayment. Simple slope analysis reveals that at there were significant differences in the repayment amount between low vs. high SCCE for regular participants $(b=-$ $81.70, \mathrm{t}==-5.55, \mathrm{p}<0.001)$. In contrast, for autopay participants, the effect of SCCE on credit card repayment is not significant $(\mathrm{b}=-.21, \mathrm{t}=-.01, \mathrm{n} . \mathrm{s})$.

Within high balance: the moderated regression results revealed the main effect of autopay $(b=-317.39, t=-3.57, p=<0.001)$ and main effect of SCCE $(b=-135.10, t=-3.88$, $\mathrm{p}=<0.001)$ on credit card repayment. The interaction effect between autopay and SCCE on credit card repayment is not significant $\mathrm{p}>.5$ ).

Within control: the moderated regression results revealed the main effect of autopay $(b=-301.69, t=-2.13, p=<0.001)$ and main effect of SCCE $(b=-156.24, t=-2.58, p=<0.001)$. The interaction effect between autopay and SCCE is not significant $\mathrm{p}>.5$ ). 
Figure 2 shows the interaction effect discussed above for the two account balance experimental conditions: low account balance (panel A), high account balance (panel B). Patterns in control condition is similar to panel B. Based on these results, H3 is supported.

A. Low Saving

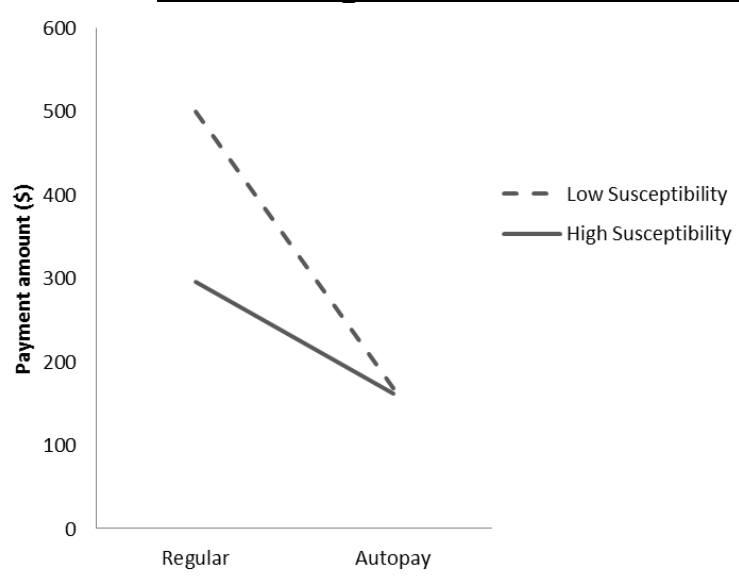

B. High Saving

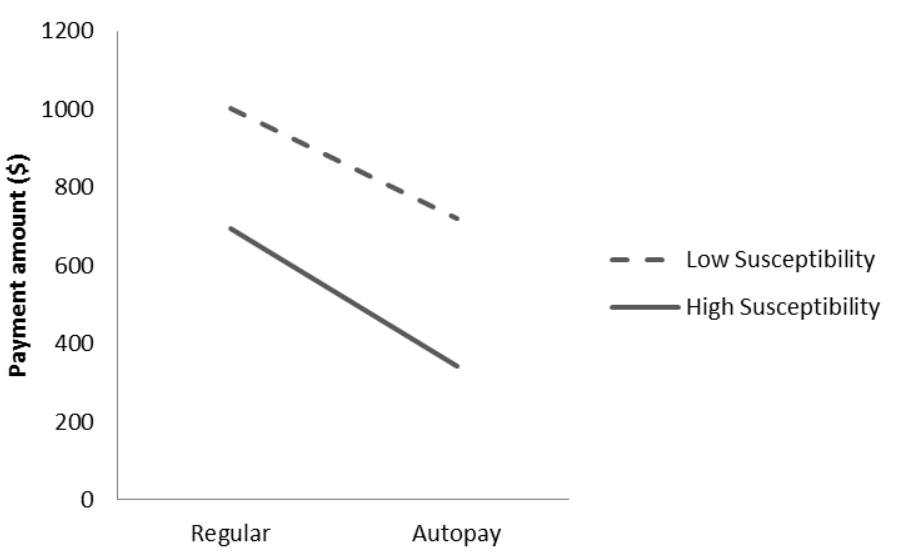

\section{General Discussion}

Automated payment is not as virtuous as many have assumed. In fact, autopay facilities encourage may reduce consumers' long-term goal of debt repayment by craftily shifting attention away from superordinate goals to the more manageable and rewarding subgoals. We recommend that policy developers and practitioners should exercise caution in promoting the use of automated payment to enhance financial management. Such recommendations should come with a set of actionable guides to reduce debt levels in shorter time.

Our findings also suggest that separation of many credit and debit accounts means that people tend to categorize debt and saving into separate mental accounts. This affects people's ability to make informed repayment decisions, which should reflect one's real ability to pay. Interventions that help people to accurately measure their real financial capabilities are expected to raise their repayment decisions. Therefore, we suggest that policy makers and practitioners reconcile credit card and saving account in a single online platform to enhance the consumers' repayment decision.

\section{Selected References}

Besharat, A., Carrillat, F. A., \& Ladik, D. M. (2014). When Motivation Is Against Debtors' Best Interest: The Illusion of Goal Progress in Credit Card Debt Repayment. Journal of Public Policy \& Marketing, 33(2011), 143-158.

Gal, D., \& McShane, B. B. (2012). Can Small Victories Help Win the War? Evidence from Consumer Debt Management. Journal of Marketing Research, 49(4), 487-501.

Salisbury, L. C. (2014). Minimum Payment Warnings and Information Disclosure Effects on Consumer Debt Repayment Decisions. Journal of Public Policy \& Marketing, 33, 4964.

Soll, J. B., Keeney, R. L., \& Larrick, R. P. (2013). Consumer Misunderstanding of Credit Card Use, Payments, and Debt: Causes and Solutions. Journal of Public Policy \& Marketing, 32, 66-81.

Sussman, A. B., \& O'Brien, R. L. (2015). Saving for a Purpose: Financial Consequences of Earmarking to Encourage Savings. Journal of Marketing Research, 1-66. 